\title{
Redesigning the Traditional Business Gaming Process - Aiming to Capture Business Process Authenticity
}

\author{
Timo Lainema \\ Turku School of Economics and Business Administration \\ Turku, Finland
}

timo.lainema@tukkk.fi

Executive Summary

The constantly changing business environment has forced many organizations to move away from focusing on individual tasks and functions to focusing on more integrated and coordinated ways of work. Higher-level business and information systems (IS) education is also in a state of change, as the traditional curriculum does not coincide with business realities. The mission of IS is shifting from developing and supporting information processing applications to developing, managing and supporting the information technology infrastructure for the entire organization. This requires knowledge of business operations. As educators in universities we should take these changes into consideration when we plan IS curricula. This means critical examination of the content of teaching.

On the basis of the evidence from some business school and IS education literature, the authors point out the need to teach the cross-functional nature of business operations. In this paper we present an example of a business learning environment that presents business organizations as dynamic, time dependent networks of business transactions. We aim at representing real-world complexity and authenticity in the learning environment. This aim is justified by introducing the constructivist view of learning which supports the use of learning environments which capture the learning context as a whole. According to the constructivist principles learning tasks should also be relevant and the reason for solving problems must be authentic to the context in which the learning is to be applied.

The learning environment introduced in this paper provides the learner with control over the learning activity and also enables the re-creation of highly realistic situations in which the learner personally experiences the content of instruction. We are challenging the dominating batchprocessed method of running business games. Our proposition is based on continuous processing, which is relevant especially from the point of view of training causal, time-dependent cross-

Material published as part of this journal, either on-line or in print, is copyrighted by the publisher of the Journal of Information Technology Education. Permission to make digital or paper copy of part or all of these works for personal or classroom use is granted without fee provided that the copies are not made or distributed for profit or commercial advantage AND that copies 1) bear this notice in full and 2) give the full citation on the first page. It is permissible to abstract these works so long as credit is given. To copy in all other cases or to republish or to post on a server or to redistribute to lists requires specific permission and payment of a fee. Contact Editor@JITE.org to request redistribution permission. functional business operations. We also present some findings from using a dynamic and realistic business process learning environment in company in-house training sessions and argue the applicability of the learning environment in university settings. As a conclusion we note that continuous processing in simulation gaming environments reveals the natural complexity and process nature of business op- 
erations better than batch-processing. Along with the processes, the game participants can also draw conclusions about causal dependencies between decisions and their outcomes. With these kinds of dynamic models participants discover that in complex systems cause and effect are separated in time and place. Continuous processing presents authentic tasks rather than abstractive instructions. Also the process nature increases the realism of the gaming experience. Realism in the game model also increases the enjoyability of the gaming experience, and this probably further enhances learning. These findings speak for the use of learning tools that represent authentic tasks rather than abstractive instructions.

Keywords: IS Curriculum, Business Process Training, Business Gaming, Interactive Learning, Computer-Based Learning, Simulation Gaming.

\section{Background}

Higher-level business and information systems (IS) education is in a state of change, as the traditional curriculum does not coincide with business realities. There is a clear move in business schools away from viewing programs as solely concerned with the transmission of content, knowledge and skills, towards developing deeper intellectual skills and the capacity to think independently (Prince \& Steward, 2000). There is also a lack of integration of all the "traditional" functional areas (e.g. accounting/finance, marketing, operations, management) in relation to evolving overall business models and strategies (Selen, 2001). Business schools and faculties have a linear, disciplinary focus on business education, which neglects the introduction of process perspective needed in the business curriculum (Walker \& Black, 2000). The range of teaching techniques must be extended to include process-oriented approaches (Leitch \& Harrison, 1999).

This development also has some implications for IS education. Within IS the major debate about technical versus managerial and business skills started during the late 1960s and early 1970s. During this mainframe era the IT organization was a reactive, cost-control enabler, not an initiator of strategic efforts. As personal computers and local area networks were introduced during the 1980s, the IT organization had to adapt to a more business-responsive environment, characterized by shorter software development cycle times and the need to satisfy user clients (Byrd \& Turner, 2001). The studies in the 1990s reported that today's IT professionals need a combination of managerial, business, interpersonal, and technical skills to service their organizations. The IS organization has begun to play a service role by providing training, consulting, and trouble-shooting (Gupta \& Wachter, 1998). The most important IS activity in the future is to analyze business problems and IS solutions (Lee, Trauth, \& Farwell, 1995). The mission of IS is shifting from developing and supporting information processing applications to developing, managing and supporting the information technology infrastructure for the entire organization. Thus, in-depth knowledge of business operations is a prerequisite. Trauth, Farwell, and Lee (1993) describe the employers' vision of the future IS professional as an integrator devoting as much effort to analyzing business problems as to developing technical solutions. Professionals will possess traditional IS skills but will be focused on integration of applications and business functions rather than systems development.

In their study, Lee et al. (1995) found out that among the highest rated skills of IS professionals in the future are: ability to learn about business functions, ability to interpret business problems and develop appropriate technical solutions, ability to understand the business environment, and knowledge of business functions (these four skills were among the seven most needed skills). Work (1997), when citing some studies about whether IT projects live up to their expectations, notes that the causes of failure in unsuccessful projects are primarily human, not technical: poor management, inadequate training of users, ignorance of the need to revise processes and procedures, organizational politics. Work (p. 334) argues: 
Unfortunately, the misconception that technology, particularly information technology, is an end, rather than a means to an end, permeates government, business education, and the mind of the public.

All this has made it necessary to rethink the IS education paradigm. Work (1997) discusses the findings of Lee et al. (1995). He claims that there is little that is unique to an IS curriculum. The skills in demand are features of general education. He notes that business knowledge hardly differentiates an IS education. The same is true of technical management. He further notes that technology might distinguish IS programs from others, yet Lee et al.'s study ranks technological knowledge at the bottom of the list. Work summarizes that practitioners regard information systems as essentially interdisciplinary. Thus, the most distinctive aspect of IS is not a single subject, but the relationship among several. This requires education which stresses the interconnectedness of all areas of learning rather than their separateness.

The study of IS is about brokerage, coping with the complexities that emerge out of consequences of applying technology and self-organizing systems that are created in the choices and actions of people and their consequences (Angell, 1997). This necessitates that IS professionals have a firm grasp of business functions. But very often the IS curricula lack the integrative and pragmatic IS education most demanded by business professionals. Gupta and Wachter (1998) quest for education that would teach the students how different business subjects fit together and mutually impact one another. Furthermore, the socio-technical complexity of live organizations and the need of interpersonal skills should be captured.

What we present in this paper is an example of a business learning environment that can answer to some of the challenges described above by presenting business organizations as dynamic (time dependent) networks of myriads of business transactions. This view on business differs from the traditional way of seeing, e.g., business games as theory-driven rehearsal tools for the highest (aggregate information) level corporate decision-making. Our proposition is based on continuous game processing that describes the real nature of businesses processes. Continuous processing in business games illustrates causality and time-dependency of cross-functional business operations. Continuous processing also describes business problems that are complex, subjective and dynamic. Before discussing the continuous process-oriented/transaction-driven method of business gaming in more detail, we justify our aim of presenting real-world complexity and authenticity by introducing a modern view of learning.

\section{A Modern View of Learning}

The basic idea in constructivism is that students learn from thinking, and technologies can support this learning if they are used as tools that help learners to think. According to the constructivist learning paradigm, technologies can be effectively used as tools to construct knowledge with not from, like in programmed instruction or computer-assisted instruction frames (Jonassen, Peck, \& Wilson, 1999). Furthermore, the principles of constructivism suggest that meaning making is a process of negotiation among the parties through dialogues. This dialogue occurs most effectively within communities where people share their interests and experiences. Learners working in groups must socially negotiate a common understanding of the task and the methods. People naturally seek opinions and ideas from others. Technologies can support this conversational process by connecting the learners with each other.

According to the constructivist learning principles, instruction should not focus on transmitting plans to the learner but rather on developing the skills of the learner to construct (and reconstruct) plans in response to situational demands and opportunities (Duffy \& Jonassen, 1992). Thus, instruction should provide contexts and assistance that will aid the individual in making sense of the environment as it is encountered. Emphasis should be shifted from the retrieval of intact knowledge structures to support the construction of new understandings. Learners should be able 
to bring together from various knowledge sources an appropriate ensemble of information suited to the particular problem-solving needs of the situation at hand (Spiro, Feltovich, Jacobson \& Coulson, 1991).

Bednar, Cunningham, Duffy, and Perry (1992) have quite an extreme view of how constructivism differs from the old design principles of traditional behavior theory. They argue that effective sequencing or rigorous external control of instructional events simply precludes constructive activity and the possibility of developing alternative perspectives. The aim should be to facilitate situating cognition in real-world contexts and construction of multiple perspectives. By real-world contexts Bednar et al. (1992) mean that:

- $\quad$ The task is not isolated but rather a part of a larger context. We should create projects or environments that capture a larger context in which the problems are relevant.

- $\quad$ The reason for solving the problems must be authentic to the context in which the learning is to be applied.

- $\quad$ The environmental context is critical. Learning always takes place in a context and the context forms an inexorable link with the knowledge embedded within it. Thus, an abstract, simplified environment is not just quantitatively different from the real-world environment but it is also qualitatively different. Authentic learning environments may be expected to vary in complexity with the expertise of the learner.

A goal of this approach is to create shared environments that permit sustained exploration by students and teachers and enable them to understand the kinds of problems and opportunities that experts in various areas encounter and the knowledge that these experts use as tools. The following principles are suggested to create meaningful learning environments (Cognition and Technology Group at Vanderbilt University, 1992):

- The problem situation information is displayed in the form of dynamic images: the problems to be communicated can be much more complex and interconnected than in written format and the students can form rich mental models more easily.

- Narrative format to represent information (meaningful context for problem solving).

- Generative learning format. Learners are allowed to determine themselves what the outcome of the exercise will be (motivation of the learners).

- $\quad$ Embedded data design. All the data needed to solve the problems are to be embedded within the narrative. The problems are not explicitly formulated in the environment, but incidentally presented in the story.

- $\quad$ Problem complexity. Students cannot be expected to learn to deal with complexity unless they have an opportunity to do so.

- $\quad$ Links across the curriculum (to introduce topics from other subject matters).

Learners tend to generate higher-level reasoning strategies, a greater diversity of ideas and procedures, more critical thinking, and more creative responses when they are actively learning in cooperative groups (Leidner \& Jarvenpaa, 1995). Virtual realities - like the construction described in this paper - are based on the assumption that the most effective learning is that which is experiential, or based on actual experience in a context that is similar to where learning has to be applied later. A virtual reality supports constructivist and cooperative learning. Students work together to construct the virtual world by contributing their own views of how the reality should operate. This is further supported by Passerini and Granger (2000) who note that simulations, virtual realities and learning networks provide the learner with control over the learning activity, and 
also enable the re-creation of highly realistic situations in which the learner personally experiences the content of instruction and creates his own knowledge.

This view of learning and the design principles describe the learning situation we are seeking well: IS professionals should join team-learning sessions with professionals from different business functions to discuss common cross-functional business problems. This kind of dialogue could lead to enhanced business process perception of all the participating parties.

\section{A Proposition}

Our proposition is challenging the traditional and dominating batch-processed method of running business games. The proposition is based on continuous processing which - according to our experiences - better describes the real nature of businesses. Continuous processing in business games is relevant especially from the point of view of training causal, time-dependent crossfunctional business operations. Continuous processing describes business problems that are complex, subjective and dynamic. Continuous processing also enables an adaptive and cyclical manner of representation of business functioning. Before more closely presenting the learning tool of the paper, we will further argue for some characteristics relevant in present day business education.

In our view, business process oriented teaching requires certain properties from the learning environments. First, there is a need for business decision-making cases that represent the characteristics of the real world environment. Business students need to understand the dynamics, causal dependencies and complexity of business operations and how different business subjects fit together and mutually impact one another. The students should be able to cope with the complexities of self-organizing systems that are created in the choices and actions of people and their consequences.

Secondly, the learning environment should be dynamic in the sense that it should be able to present different cases, or business environment scenarios. This offers the students a possibility to construct interpretations, appreciate multiple perspectives, develop and defend their own positions while recognizing other views, and becoming aware of and able to manipulate the knowledge construction process itself. For example, students could examine companies that have different kinds of production hierarchies and how these hierarchies affect, for instance, the purchasing process or cash flow and the need for external financing.

Finally, business schools and their IS departments (as well as companies) need learning tools that promote business process understanding and how a business operates as a whole. Business education has not provided a broad, integrating, or realistic experience in the business curriculum. The core curricula of most business schools focus primarily on only two dimensions, functional knowledge and skills. This view is not consistent with cross-functional process managed organizations (“MBA: Is the Traditional Model Doomed?” 1992).

Walker and Black (2000) note also that there are limited teaching materials to provide a basic business education consistent with a process view. Walker and Black mainly discuss the possibility of obtaining customized textbooks by selecting chapters from various textbooks to form a customized process-oriented text. However, there have been some experiments within IS that include cross-functional educational goals and the use of simulation. Zack (1998) introduces a course with many characteristics similar to our proposal. He notes that attaining a practical level of knowledge about systems integration requires a sufficiently complex, real-world environment. Zack's motivation for the use of simulation is similar to ours: the ability to analyze business problems and to apply IS solutions to those problems will remain the highest priority among the IS professional skills. Zack notes that when using simulations, the primary trade-off is between control and realism. Sending students to the field offers realism but the lack of control over content, 
context, and the timing of the experience often results in problems. He further argues that the marketplace demands a more applied approach to teaching. Systems design requires managing complexity and ambiguity and this aspect should be included in educational experiences to afford real-world learning.

As other benefits from using simulations, Zack mentions that students learn not only the technical material but also human relationship, collaboration, and communication skills. Furthermore, the role of subsystems, their relationships, and the potential conflicts among them can be made visible to the participants (Zack, 1998). The simulation Zack introduces has a different primary aim than our proposal: we are aiming at giving a holistic business-process oriented view on business organizations as Zack is aiming at designing, developing, implementing, and operating information systems.

As a conclusion, what we are seeking is something Trauth et al. (1993, p. 299) quest for:

Learning about integration (of applications, data, and business functions) requires a sufficiently complex environment so that students can observe how disparate parts are brought together.

Today, the vast majority of business games follow the batch-processed manner. Already Forrester (1961) has described (batch-processed) business simulations as black boxes, which do not allow the participants to see the events and transactions happen. Forrester calls this kind of training external teasing which is disappointingly unrewarding. Forrester states (p. 358): "The emphasis in the business game is on the external manifestations, not on the internal structure and its implications.” The main stream of business games still - almost 40 years later - represents business processes and transactions hidden from the business game participants. Of course, the aims of the use of business games can be diverse and batch-processed business games are often invaluable training tools when teaching strategic management. However, from the business process perception point of view business games have not been relevant educational tools. Despite this we feel that the kind of experiential learning taking place in business game sessions is much too valuable to be neglected in process oriented training. As a solution we are looking for a method to describe business processes with business games and to allow the game participants to realize the process nature of cross-functional business operations.

Business games have not been included in business process management discussion unlike process prototyping and simulation tools. However, we see some potential in business games to support employees' process perception. This is possible if the processing method of business games describes the flow of time explicitly and continuously. The advantage of business games, in contrast to process simulation techniques, is that business games are interactive. By this interactivity we mean that the participants are part of the business process and are in continuous interaction with other participants, customers, suppliers and funding.

Chiesl (1990) mentions that an interactive business simulation would offer the students a more realistic environment than the present fixed-time format business game. Thus, participants experience a business environment that has the appearance of being true and real. On the other hand, Patz (1990) notes that a simulation may run continuously with participants entering new decision rules at their discretion or as indicated by current market conditions. Overall, this means that simulations may assume the day-to-day character of ongoing business while encouraging the development of long-range strategies.

Kueng and Kawalek (1997) give us some encouragement in constructing continuous game models by arguing that (p. 21):

It is common to describe business methods as a number of discrete steps. However, intuitively it seems unlikely that requirements will be elicited in one and only one step. Given that we are dealing 
with problems that are complex, subjective and dynamic, it would seem to be better to take an adaptive and cyclical approach.

Without going into details, we would like to mention that continuous processing has some additional characteristics not met in batch-processed games. In continuous gaming, the nature of deadlines differs from the deadlines in batch games. In batch games the only deadline is the deadline for the whole decision batch, defined by the game operator. In continuous gaming the deadlines are clock bound and set partly by the decision makers (for example, in the sales orders the players promise a certain delivery time for their customers and are then bound to deliver their goods according to this) and partly by the environment (the customers may order whenever they decide and then the players need to respond to this in time). Also in batch games the periodic regularity in which work is completed is clear; it is the period of simulating one cycle from decisions to results. In continuous gaming the cycles are simultaneous, successive, their frequency may be very fast, and they are not necessarily regular. Both of these characteristics make the learning experience between the two modes very different. Our belief is that these characteristics of continuous gaming make the learning experience more authentic than in batch-processing.

Why have these kinds of structures not been constructed before? Patz (1990) may give us one possible explanation: simulation purposes, for the most part, are decided by coding convenience rather than pedagogical, conceptual, or theoretical relevance. Similar findings come from the IS literature. Leidner and Jarvenpaa (1993) note that computers are merely used as vehicles for teaching procedural material, rather than teaching concepts. This is because it takes a tremendous time to redesign a course for computer-based teaching methods. Still, they note that interactive student use of computers is a prerequisite for effective computer-based teaching methods.

\section{Realgame}

The learning environment presented in this paper aims at responding to the demands and requirements presented above. This on-line processed game (Realgame) was developed between 1997 and 2000. Realgame is validated through cooperation with an industrial partner in the game construction phase. Through this cooperation the game was designed to describe the actual business operations and functions of a business unit of a large company operating in the food stuffs industry. Realgame has been used some 35 times in teaching between 1999 and 2003, mainly in university classes but also in companies from 2001 onwards.

In Realgame there are 6-8 companies competing against each other, and the markets, suppliers and funding organizations are common to all participating companies. The companies are steered by groups of three participants. The customers on the game market server trigger demand according to the offers (sales price, term of payment, delivery speed), image (marketing, delivery certainty), and product quality (R\&D) of the participating companies. The demand is the same for all the participating companies and the game operator can change the demand during the game.

Realgame includes a detailed materials process, starting from raw material purchases (suppliers with different prices, delivery speeds and terms of payment), incoming inventory (including alarm sizes for automatic raw material purchases), the actual production process (multiphase cell based production line, the capacity and workers in each production cell can be changed during the game), finished goods inventory, and deliveries (several different delivery methods for each market, differing between delivery speed and cost). Furthermore, the game includes functions like sales, marketing, $R \& D$, and funding. As the game describes and collects information about the detailed business transactions, the participants are able to produce detailed reports on the materials and monetary processes.

All the above mentioned functions in the game are configurable to represent different kinds of business environments. The processes of Realgame are continuous for the game participants in 
the sense that the game time is clock-driven, the smallest increment in time being one hour, and the participants are not tied to making decisions at specified points of time but can make decisions whenever they choose during the game. Furthermore, the participants see the internal and external business processes evolve, e.g., hour by hour, depending on the game parameters.

As an example of what the gaming experience might include we illustrate some typical game decisions the participants have to perform (a simulated day takes typically from 5 to 10 real world minutes in the beginning of the game, depending on how well the game operator thinks the participants are familiar with the game processes):

8 AM The participants notice that they are short of product BioCounter. There are three unfilled orders with the amount of 150 BioCounters and the inventory includes only 13 units. The participants change the final assembly production cell to produce BioCounters instead of the BioCounter DLX model. At the same time they also note that one of the production cells in the preceding production phase has run out of raw material Electronics. They order 10,000 units of Electronics from a supplier who promises to deliver the products within 2 days.

10 AM The company runs out of cash. The participants contact the bank and receive a loan of 2,000,000 euros, with interest of $4 \%$ pa, term being 12 months. The cash shows now 525,000 euros.

Noon Because of the previous incident, the participants decide to check their Accounts payable and receivable. They note that incoming cash flow will cover the outgoing expenses until the end of next week.

2 PM The participants run a market report of their company's market share within each market area. They note that they are losing their share in Europe and decide to invest in advertising in that area. A marketing campaign of 1,000,000 euros is started. They also note that this expense must be paid after two weeks.

4 PM The participants also check their market prices compared to those of their competitors. They note that they can increase the price of BioCounter in Europe but the other market areas remain unchanged.

5 PM Some customers in North-America inform that BioCounter DLX deliveries have arrived some 1-3 days late. The participants change the auto delivery method from Ship to Air freight, which will increase the delivery cost per unit by 55 euros but the deliveries should now be some 7-8 days faster. They also modify the promised delivery time in their North-American offers from 10 days to 5 days. This, they hope, will also increase demand for their products. To compensate for the increased delivery costs the price of all products for North-America is increased by $3 \%$.

6 PM The participants run the real-time income statement and note that their Profit-\% has increased by 1.2 percentage units compared to the profit one week ago. Also some other key figures (like ROI, inventory turnover, and debt-equity ratio) have got better.

The tasks described above are also presented in Figure 1 (only the tasks mentioned above). As such the figure seems to be quite simple and straightforward. But as the process is continuous the different transactions keep occurring again and again. In other words, the process described in Figure 1 is cyclical and each of the transactions has its own time of occurrence. Furthermore, the time of occurrence for each transaction is not necessarily predetermined but many of the events take place without any warning in advance (like customer orders). This, we feel, describes the natural complexity and process structure of organizational functioning.

As one might anticipate from the above description, decision-making takes place under conditions of high time pressure. The process becomes even more demanding as it requires agreement from all the participants of the group. 


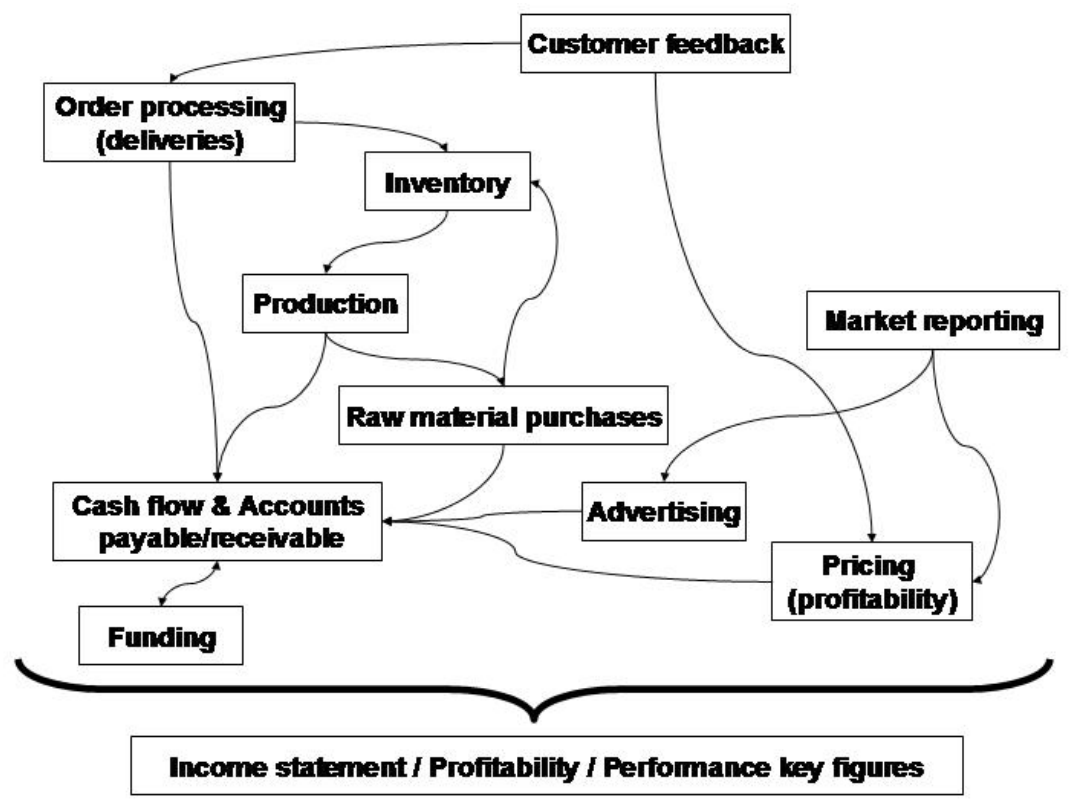

Figure 1: Some business tasks and processes of Realgame.

Realgame is highly interactive in several ways, as depicted in Figure 2. First, there is collaboration between the participating students within each team around the same computer (arrow 1). Secondly, the participants enter their decisions to the game decision-making application (computer model of a manufacturing company; arrow 2) in their computer. Thirdly, each company application is in continuous interaction with the market server (arrow 3). Finally, the participating groups are connected to each other through the market information they receive, but they may also communicate 'informally' with each other during breaks.

By using Realgame we believe that the students gain an appreciation for what business processes are and how these processes can be represented as a cross-functional flow of information. Furthermore, the participants have skills with which they are expected to be able to understand the requirements of wellfunctioning processes. The focus is continuously on several business disciplines and the systems nature of business is revealed. At the same time it is possible to incorporate some technology based skills into the training. e.g. students can create their own reporting

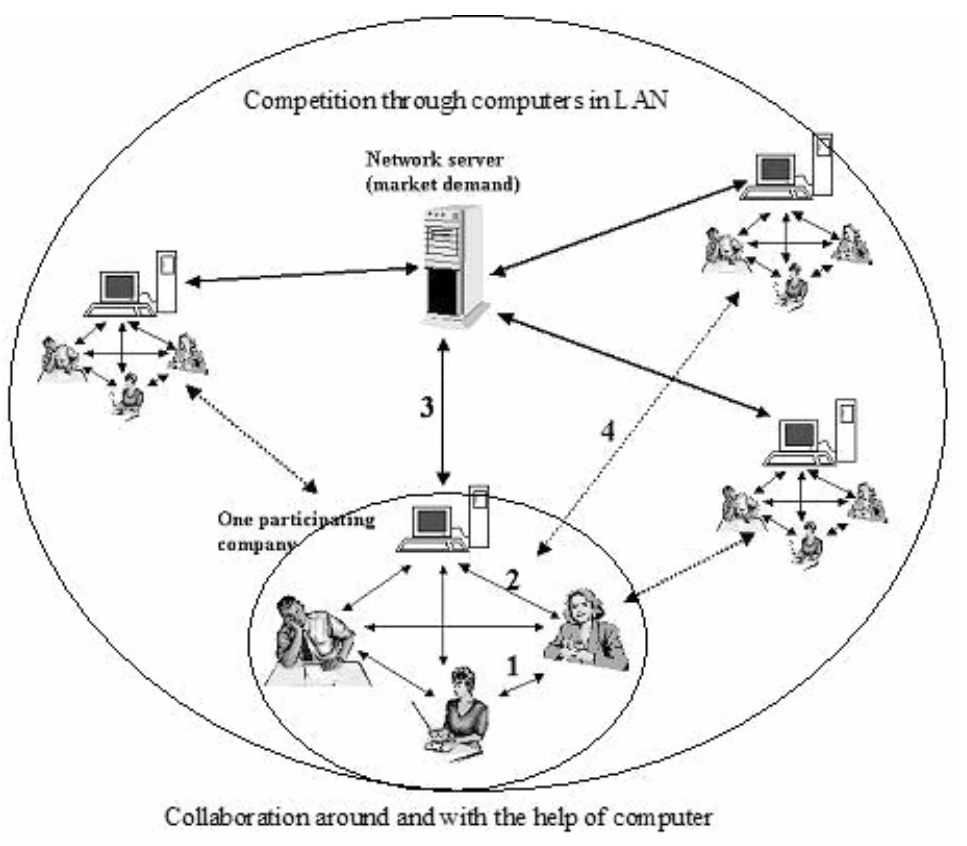

Figure 2: Interactivity in Realgame.

(Nurmi \& Lainema, 2002) 
and decision support systems on the transaction specific databases the game produces. As an example of this kind of data, Figure 3 represents the cash flow table of the game. These data are saved in a database table on which the students can produce SQL or Query by Example (QBE) queries, or import the data into a worksheet application to produce calculations.

\section{The Cases}

The construction has now been in production use both in five different universities and in companies from early 2001. We believe that when evaluating Realgame as a process training tool, the best evaluators are professionals who work in true business life and have several years experience in how business organizations actually function. This is why we are not going to present findings from student use in this paper, though this information has also been collected.

\section{The Training Settings}

The case studies analyzed here are from three company game training sessions. All the sessions were organized by a continuing learning center of a Finnish technical university. Table 1 shows the profiles of the survey respondents and the learning settings.

The game sessions were a two day module (one day in case of session A) in an educational program lasting more than two years. The participants had these two day modules every month or every second month. The theme of learning in the game sessions was managing a holistic business organization. This theme was loosely connected to the themes of the previous training modules which dealt with strategy or finance.

\section{The Participants}

It is obvious that the participants had quite diverse educational and work experience backgrounds. They also represented great professional experience, as the average work experience of all the respondents is 17.4 years. This, we believe, makes the participants' perception of the usefulness of gaming quite reliable. Table 1 introduces the three training settings and the participants. 
Table 1: Profiles of the survey respondents and the learning settings from the three game cases.

\begin{tabular}{|c|c|c|c|c|c|c|}
\hline $\begin{array}{l}\text { Game } \\
\text { session } \\
\text { \& date }\end{array}$ & $\begin{array}{l}\text { Game } \\
\text { duration }\end{array}$ & Company & $\begin{array}{l}\text { Participants/ } \\
\text { respondents } \\
\text { (response } \\
\text { rate) }\end{array}$ & $\begin{array}{l}\text { Positions and educa- } \\
\text { tional background of } \\
\text { respondents }\end{array}$ & $\begin{array}{l}\text { Work experi- } \\
\text { ence (avg.) }\end{array}$ & $\begin{array}{l}\text { Played a } \\
\text { busi- } \\
\text { ness } \\
\text { game } \\
\text { before } \\
\text { (N) }\end{array}$ \\
\hline $\begin{array}{l}\text { A: } \\
10 / 2001\end{array}$ & $\begin{array}{l}\text { One day } \\
(7.5 \mathrm{~h})\end{array}$ & $\begin{array}{l}\text { Two: } \\
\text { 1. Information tech- } \\
\text { nology manufac- } \\
\text { turer. } \\
\text { 2. Medical } \\
\text { instruments manu- } \\
\text { facturer. } \\
\end{array}$ & $\begin{array}{r}17 / 14 \\
(82 \%)\end{array}$ & $\begin{array}{l}\text { Middle and upper man- } \\
\text { agement positions. Educa- } \\
\text { tional background diverse } \\
\text { ( } 5 \text { in natural sciences, } 4 \text { in } \\
\text { technical sciences, } 4 \text { in } \\
\text { business, and one both in } \\
\text { technical and business) }\end{array}$ & 12.8 years & 10 \\
\hline $\begin{array}{l}\text { B: } \\
11 / 2001\end{array}$ & $\begin{array}{l}\text { Two } \\
\text { days } \\
(13.5 \mathrm{~h})\end{array}$ & $\begin{array}{l}\text { Aviation compo- } \\
\text { nents manufactur- } \\
\text { ing and armaments } \\
\text { industry. }\end{array}$ & $\begin{array}{r}17 / 16 \\
(94 \%)\end{array}$ & $\begin{array}{l}\text { Foremen in production or } \\
\text { of technical inspection } \\
\text { groups, and group leaders. } \\
12 \text { had technical education } \\
\text { (college level), others sec- } \\
\text { ondary school graduate, } \\
\text { vocational, other, or com- } \\
\text { mercial (one of each of } \\
\text { these) }\end{array}$ & 20.0 years & 2 \\
\hline $\begin{array}{l}\text { C: } \\
6 / 2002\end{array}$ & $\begin{array}{l}\text { Two } \\
\text { days } \\
(13.5 \mathrm{~h})\end{array}$ & $\begin{array}{l}\text { Aviation compo- } \\
\text { nents manufactur- } \\
\text { ing and armaments } \\
\text { industry. }\end{array}$ & $\begin{array}{r}18 / 16 \\
(89 \%)\end{array}$ & $\begin{array}{l}\text { Diverse: engineers, pro- } \\
\text { duction foremen. One with } \\
\text { commercial education, all } \\
\text { the rest with technical edu- } \\
\text { cation. }\end{array}$ & 18.7 years & 4 \\
\hline All & & & $\begin{array}{r}52 / 46 \\
(88 \%)\end{array}$ & & 17.4 years & 16 \\
\hline
\end{tabular}

\section{Methodology}

In these cases we conducted a survey and at this stage no observational studies were used. The research presented in this paper concentrates on how the participants experienced the gaming sessions and how useful they found the game context in representing business processes. The primary unit of analysis was the gaming session and the participants in the game. The intervention to be studied was the participants' gaming experience and learning. The possible outcomes to be described included a) participant opinions on the usefulness of the game as a business process learning tool and b) learning self-assessment. The question selection was based on the business phenomena represented in the game, to develop a survey instrument to be used systemically in each separate training session.

The questionnaire has changed slightly during the last 1.5 years (due to experiences from both gaming sessions in universities and company settings), but the main structure has remained the same. The first part of the questionnaire outlines participant background (questions 1 to 3: work experience, education, whether they had participated in business games before).

The second part of the questionnaire consists of 15 questions using a structured seven point Likert scale. The structured questions of the second part measure the participant opinions on how well they thought the game represented, e.g., business functions, flow of time in business organizations, enjoyability of gaming, etc.

The third part of the questionnaire consists of 2 or 3 unstructured open ended questions. Here the participants were asked to tell whether the game helped them to form a holistic view of the functioning of a manufacturing company, what they thought they learned through gaming, what they thought about the continuous nature of the game, and if they found Realgame motivating and useful. 
The game participants answered the questionnaire immediately after the gaming sessions. The questionnaire timing was not perfect in the sense that the participants were usually quite exhausted after the intensive game and this is evident especially in the very short answers to the open-ended questions.

\section{Results}

We will now compare the participant responses to our search for relevant skills described at the beginning of this paper (i.e., a need for business decision-making cases, which represent the causal dependencies and complexity of business operations / a need for learning tools, which promote business process understanding).

The results from the first part of the questionnaire are shown in Table 1 (three last columns). As already noted, the participants had an average work experience of 17.4 years. The majority of the participants had a technical education but some had a degree in natural sciences or economics. Only the participants of session A had previous experience in business game training.

The second part of the questionnaire included seven questions which are to do with crossfunctional business processes. These questions are marked * in Figure 4. The averages of the answers to these seven themes vary from 4.1 to 5.7 in session A, and from 5.1 to 5.9 in sessions B and $\mathrm{C}$. We think that the results from sessions $\mathrm{B}$ and $\mathrm{C}$ especially show that Realgame includes great potential to be used as a process training tool, if only enough time is used for the training (in sessions B and C where more time was used, the participants considered the game less complex,

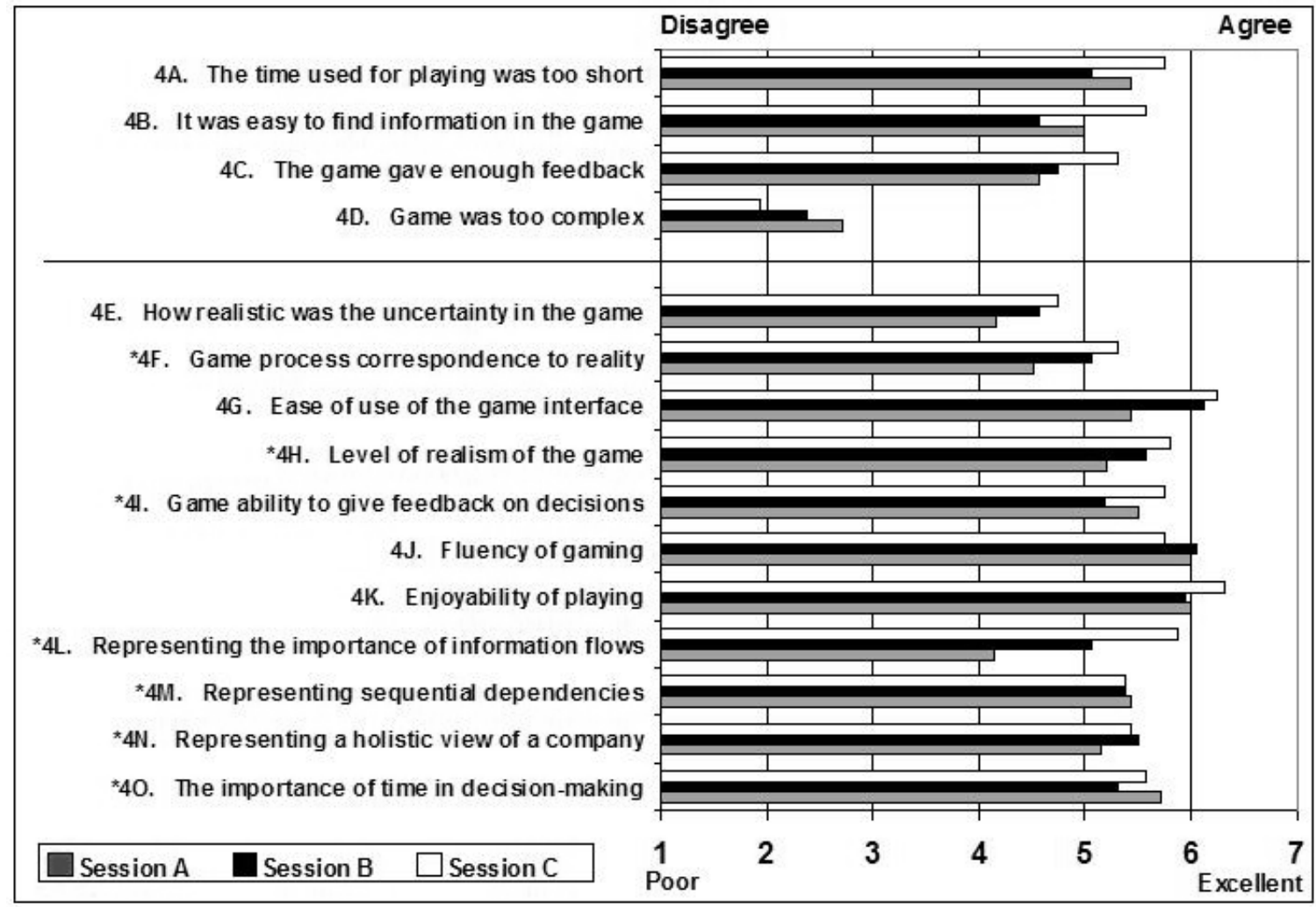

Figure 4: The three game training sessions and participant feedback (averages of answers) compared by different game training themes and properties. The scale for the first four questions was from Disagree (1) to Agree (7) and the scale for the rest of the questions was from Poor (1) to Excellent (7). Questions concerning business processes are marked *. 
and in general sessions $\mathrm{B}$ and $\mathrm{C}$ show better results).

The game received the best numerical results in terms of:

- $\quad$ The ease of use of the game interface: average of the three sessions 5.96, standard deviation of all the three sessions 0.94

- $\quad$ Fluency of gaming: 5.93/1.02

- $\quad$ Enjoyability of gaming: 6.09/0.86

Most of the results improved with time (from session A to B and C) and we think that this happened because of three factors:

1. In training sessions $B$ and $C$ the training lasted longer than in session $A$ (13.5 hours versus 7.5 hours). Thus, the participants had more time to get into the decision model in sessions $\mathrm{B}$ and C. Support for this assumption can be found in the answers to question 4D: Game was too complex. Participants in training A felt more often that the game was too complex than those in sessions $B$ and $C$ (although in none of these sessions the participants found the game to be very complex).

2. The game operator (the author of this paper) gathered from each session experience about how the game should be carried out and this increased experience has probably lead to better quality training sessions.

3. The game interface has also been developed slightly between the training sessions as minor problems with the interface detected during training sessions have been solved. This can especially be seen in answers to question $4 \mathrm{G}$.

After the long gaming session days it was somewhat difficult to get the participants to answer the open ended questions in the third part of the questionnaire, but there are some comments that support our assumption that continuous processing describes the true nature of business operations well.

The participants' general attitude towards the gaming experience was very positive. Negative attitudes were represented in none of the questionnaires towards either the game as a learning tool or continuous processing in general. The only negative comments were given about the hasty nature of the training (video-game-like shooting) session; some felt that more time should have been used to analyze the game situation. We will now reflect on the answers dealing with the skills we found relevant when discussing the IS curricula at the beginning of this paper.

The answers to the question "Did the game help you to form a consistent holistic view of the business of a manufacturing company and the factors influencing to it?" were very positive: $78 \%$ were clearly positive (answers like "Yes it did", or "As a novice, I would say that surprisingly well"). $6.5 \%$ of the answers were neutral (no clear stand taken), 13\% were left blank and only one (2\%) were clearly negative: "The game was more like video-game-like shooting than something facilitating analytical consideration.”

The averages of answers to question $4 \mathrm{~N}$ already showed that the participants thought that the game gave a holistic view of business operations (i.e., represented a process-oriented approach where cause and effect can be connected to each other). According to de Geus (1988) one reason for putting mental models into computers is that in working with dynamic models, people discover that in complex systems cause and effect are separated in time and place. He mentions that to many people the insight into these causal phenomena is counterintuitive, thus, we are not able to find other trigger points than the most immediate causes to create the requested effects. The use of dynamic models helps us to discover other trigger points, separated in time and place from the desired effects. Some answers to question 5 "Did the game help you to form a consistent ho- 
listic view of the business of a manufacturing company and the factors influencing it?" give support for this claim: "Very well, every sector is important in operations." or "Well. Timing in capacity. Market price + sales terms (maybe were emphasized). Offer-order-costs-capacity-and so on".

The following answers also describe the game's ability to deliver a cause-effect relationship view: "One could see in practice that if some part is wrong then also the other cells take on." or "Helped to figure out the cause effect relationships of different decisions and to interpret the key figures learned during the theory part".

What the participants felt they had learned during the game varied considerably. The sixth question was "What did you learn during gaming? What do you feel was the most important thing you learned?" Again the holistic structure of the game received support: "I learned to see the whole economic process, what is included in it. The most important thing I learned was the management of production." Also, cause-effect relationships were mentioned: "The relationships between different parts, their interdependencies; the balance between demand and supply; the sizing of capacity to correspond demand."

Like in the answers above, several participants mention that the materials process crystallized to them during gaming. The participants were also able to connect the materials process to sales and offers (answers to the sixth question): "Purchases-offers-sales. Things clarified notably (I work in production myself)." or "It is important to get the materials process and production to function in a right way and efficiently. To react to market changes." These were only some of the answers mentioning the materials process and its connection to sales and customers. Clearly, this connection and balance between the core materials process and demand was a central learning theme.

Some participants connected the materials process to the lapse of time (and, thus, to continuous processing) "The temporal influences of production capacity and pricing effects well represented."

Some learning was also connected to strategic management and the role of the supportive business functions (accounting, investment planning, pricing, and decision-support). The following are answers to the sixth question "What did you learn during gaming? What do you feel was the most important thing you learned?”:

The many flourishes of the income statement.

The importance of the flow of the monetary process.

The meaning of cash flow.

The importance of investments;...

The importance of pricing. To follow the actions of other companies; the temporal and quantitative adjustment of production factors; the importance of decision-making.

Interpreting key accounting figures and making corrective decisions based on those and recognizing the targets.

The importance of a reporting system.

Question 7 in the questionnaire was (asked only after session C): "Was the continuous nature of the game a significant factor if you consider learning and understanding?" The following answers describe the attitude of the participants towards the continuous nature of the game (all responses were positive):

Real-time processing was essential and emphasized the importance of fast solutions.

Real-time processing reveals weaknesses. 
There are important factors that need to be followed all the time.

Real-time processing is really good because of the continuous scanning of the markets.

Was significant. Taught that you cannot rest with the markets.

A small amount of stress is only a good thing.

The other comments received (free comments) on the gaming sessions included, among others:

The tempo of the game was too fast. Too little time was left for planning and analyzing the situation.

Awoke automatically a desire to compete and to do well.

The time used was too short, the game ended before you got totally into it. The holistic picture took shape better and better towards the end.

\section{Discussion and Conclusion}

In this paper we have discussed some changes and demands for current IS education. We have argued for business process training and the use of tools that aim at representing business processes by providing a natural representation of the real world. On the basis of this we have introduced a learning tool that is an example of how computerized learning environments could be enhanced to pay attention to the cross-functional nature of business operations.

As a conclusion we can note the following. First, in the light of the comments it is clear that the game has potential as a business process learning tool. Secondly, gaming as a learning method is motivating and perhaps raises less negative attitudes than other forms of teaching. This can be explained with the findings of Leidner and Jarvenpaa (1993), who note that the most preferred methods for computer-based learning are those that (1) give the students interactive use of computers and (2) allow the students to work independently of the instructor on the computer to encounter their own problems in a classroom environment. Compared to out-of-class exercises, the presence of the instructor adds an important dimension enabling the sessions to become a vehicle for subject exploration. Thirdly, continuous processing is clearly suitable for representing business processes in an understandable way. This was very clearly expressed by the participants without a single negative comment among the questionnaire answers.

Although the results from Realgame use are still preliminary, we believe continuous processing reveals the natural complexity and process nature of business operations better than batchprocessing. Along with the processes the game participants can also draw conclusions about causal dependencies between decisions and their outcomes. With these kinds of dynamic models participants discover that in complex systems cause and effect are separated in time and place. This is also closely related to the ability to describe the importance of time in decision-making. In continuous processing the time element is present in the form of processes, but in batchprocessing this element is absent, or, at best, may emerge in the minds of the participants. Thus, continuous processing presents authentic tasks rather than abstractive instructions. Also the process nature increases the realism of the gaming experience. Realism in the game model also increases the enjoyability of the gaming experience, and this probably further enhances learning.

However, we feel that we have to further develop our data gathering methods. The structured part of the questionnaire has been used to assess the game functionality from the human-computer interaction point of view. For the purpose of evaluating and justifying the game against the demands of the first chapters of this paper the Likert scale is deemed to be inadequate. The answers to the open ended questions give some hints that continuous processing is a viable solution but this aspect requires further research. It seems that by its very nature the results of gaming work are so qualitatively different from the mere acquisition of new factual knowledge that those effects cannot be detected by traditional knowledge tests. Swaak, van Joolingen,and de Jong (1998) 
conclude that it is not clear how the effects of learning from simulation are to be measured. Further they infer that gaming working produces intuitive (or implicit or tacit) knowledge, which tends to be difficult to verbalize and to measure. Thus, in the future we should develop our questions much more towards problem solving and knowledge applying tasks as well as concept mapping assignments, because simulations are more valuable in facilitating deeper understanding and complex problem solving skills than in teaching factual knowledge.

We acknowledge that the game questionnaires used with Realgame training sessions and the participant answers to these questionnaires should be viewed as a first initial assessment. The empirical results provided in this paper are to be understood to illustrate the utility and service of Realgame for the game users (individual participants and their organization). Further evidence of the game capability to function as a tool to improve competence in representing the dynamics, causal dependencies and complexity of business operations needs to be collected in the future. The constructivist learning paradigm states that if we want to analyze the learning of the learners we need to assess the meaning that the learners have co-constructed from their interactions with the world. How can we study this? Jonassen et al. (1999) note that this can probably be done by assessing learning while it is occurring. This assessment is process-oriented. In future we are going to use other kinds of research methods, such as videotaping, interviews and concept mapping techniques.

As Leidner and Jarvenpaa (1995) note, numerous challenges remain in the area of improvements to management education, which require effort from IT researchers interested in educational environments. In fact, they list six areas in need of research. In future, we hope to be able to contribute at least in the area of Research on the added value of technology to the learning models.

We believe that the interactive and continuously processed computerized learning environments could add value in the field of business process training. Our further research will focus on this topic. We are especially interested in whether Realgame gives participants a possibility to discover conceptual relationships, explore multiple representations on business process dynamics, and immerse in the real-world relevant business context.

\section{References}

Angell, I. O. (1997). Welcome to the "Brave New World". In Stowell \& Mingers (Eds.), Information Systems: An Emerging Discipline? (pp. 363-383). McGraw-Hill.

Bednar, A. K., Cunningham, D., Duffy, T. M., \& Perry, J. D. (1992). Theory into practice: How do we link? In Duffy \& Jonassen (Eds.), Constructivism and the Technology of Instruction (pp.17-34). Lawrence Erlbaum Associates.

Byrd, T. A., \& Turner, D. E. (2001). An exploratory analysis of the value of the skills of IT personnel: Their relationship to IS infrastructure and competitive advantage. Decision Sciences, 32 (1), 21-47.

Chiesl, N. E. (1990). Interactive real time simulation. In Gentry (Ed.) Guide to Business Gaming and Experiential Learning. ABSEL.

Cognition and Technology Group at Vanderbilt University. (1992). Technology and the design of generative learning environments. In Duffy \& Jonassen (Eds.), Constructivism and the Technology of Instruction. Lawrence Erlbaum Associates.

Duffy, T. M., \& Jonassen, D. H. (1992). Constructivism: New implications for instructional technology. In Duffy \& Jonassen (Eds.), Constructivism and the Technology of Instruction (pp. 1-16). Lawrence Erlbaum Associates.

Forrester, J. W. (1961). Industrial dynamics. New York \& London: The M.I.T. Press \& John Wiley \& Sons.

de Geus, A. P. (1988). Planning as learning. Harvard Business Review, March-April. 
Gupta, J. N. D. \& Wachter, R. M. (1998). A capstone course in the information systems curriculum. International Journal of Information Management, 18 (6), 427-441.

Jonassen, D. H., Peck, K. L., \& Wilson, B. G. (1999). Learning with technology; A constructivist perspective. Prentice Hall.

Kueng, P., \& Kawalek, P. (1997). Goal-based business process models: Creation and evaluation. Business Process Management Journal, 3 (1), 17-38.

Lee, D., Trauth, E. M., \& Farwell, D. (1995). Criticall skills and knowledge requirements of IS professionals: A joint academic/industry investigation. MIS Quarterly, 19 (3), 313-340.

Leidner, D., \& Jarvenpaa, S. (1993). The information age confronts education: Case studies on electronic classrooms. Information Systems Research, 4 (1), 24-54.

Leidner, D., \& Jarvenpaa, S. (1995). The use of information technology to enhance management school education: A theoretical view. MIS Quarterly, 19 (3), 265-292.

Leitch, C. M., \& Harrison, R. T. (1999). A process model for entrepreneurship education and development. International Journal of Entrepreunial Behaviour \& Research, 5 (3), 83-109.

MBA: Is the traditional model doomed? (1992). Harvard Business Review. November-December, pp. 128140.

Nurmi, S., \& Lainema, T. (2002). Collaborative learning with dynamic business game simulation - Innovative learning environment for business education. In P. Barker \& S. Rebelsky (Eds.), Proceedings of ED-MEDIA 2002, World conference on educational multimedia, hypermedia \& telecommunications (pp. 1473-1478). Association for Advancement of Computing in Education (AACE).

Passerini, K. \& Granger, M. J. (2000). Information technology-based instructional strategies. Journal of Informatics Education and Research, 2 (3), 37-44.

Patz, A. L. (1990). Open system simulation. In Gentry (Ed.), Guide to business gaming and experiential learning. ABSEL.

Prince, C., \& Stewart, J. (2000). The dynamics of the corporate education market and the role of business schools. The Journal of Management Development, 19 (3), 207-219.

Selen, W. (2001). Learning in the new business school setting: A collaborative model. The Learning Organization,. 8 (3), 106-113.

Spiro, R. J., Feltovich, P. J., Jacobson, M. J., \& Coulson, R. L. (1991). Cognitive flexibility, constructivism, and hypertext. Educational Technology, pp. 24-33. Available at: http://www.ilt.columbia.edu/ilt/papers/Spiro.html.

Swaak, J., van Joolingen, W. R., \& de Jong, T. (1998). Supporting simulation-based learning; The effects of model progression and assignments on definitional and intuitive knowledge. Learning and Instruction, 8 (3), 235-252.

Trauth, E. M., Farwell, D, \& Lee, D. (1993). The IS expectation gap: Industry expectations versus academic preparation. MIS Quarterly, September, pp. 293-307.

Walker, K. B. \& Black, E. L. (2000). Reengineering the undergraduate business core curriculum: Aligning business schools with business for improved performance. Business Process Management Journal, 6 (3), 194-213.

Work, B. (1997). Some reflections on information systems curricula. In Stowell \& Mingers (Eds.), Information Systems: An Emerging Discipline? (pp. 329-359). McGraw-Hill.

Zack, M. H. (1998). An MIS course integrating information technology and organizational issues. The DATA BASE for Advances in Information Systems, 29 (2), 73-87. 


\section{Biography}

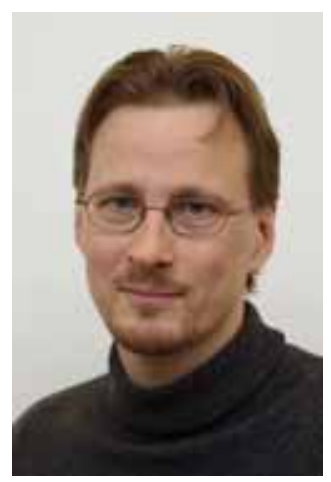

Timo Lainema has a $\mathrm{PhD}$ in Economics and Business Administration from Turku School of Economics and Business Administration (TSEBA), Finland. He acts as an Assistant Professor in the department of Information Systems Science in TSEBA. He has an experience of 16 years in using business games both in university education and in business in-house company training setting. Before enrolling in the academia to take the $\mathrm{PhD}$ he worked as an entrepreneur offering business game training to business companies. The Realgame business game described in this paper was constructed in Lainema's doctoral research project. The thesis is online at: http://www.tukkk.fi/julkaisut/vk/Ae5_2003.pdf. Lainema also provides Realgame training: http://www.realgame.fi. Partly in connection to business gaming Lainema's research interests include such topics as time in decision-making, experiential learning, complexity in learning environments, and data bases. 